\title{
Didactic Material for Preparation Observation and Estimation Content on Subject Recreational Activities in Nature
}

\author{
Nidia Esther Gómez Barrientos \\ Universidad de Oriente, Facultad de Cultura Física, Santiago de Cuba, Cuba \\ Corresponding author email: ngomezb@uo.edu.cu \\ Randy Fernández Gómez \\ Universidad de Oriente, Facultad de Cultura Física, Santiago de Cuba, Cuba \\ Email: randyf944@gmail.com
}

\begin{abstract}
Providing alternative answers to the problem of learning quality is a fundamental concern for educators engaged in the task of promoting personal growth in the teaching-learning process. The research presented refers to the inadequacies in the theoretical-practical preparation in the content of the observation and estimation in the subject Recreational Activities in Nature in fourth-year students of the Physical Culture career. In this sense, the objective was to elaborate a didactic material (Brochure) that provides the development of theoretical and practical preparation in the content of observation and estimation. The methodology that was used as a theoretical method was the analysis-synthesis, inductive - deductive, review of documents and as an empirical method the observation and criteria of specialists; As techniques, the interview, survey, and the statistical-mathematical procedure were used as a percentage calculation, which allowed us to know the theoretical and practical inconsistencies that led to the need to treat the problem under investigation. The results of the diagnosis reveal the existence of the insufficiencies that the students possess in the referred content and its relation with the diversity of didactic resources, thus elaborating the didactic material which according to the criteria of the specialists provides the student with greater motivation to appropriate the necessary knowledge about the content of observation and estimation.
\end{abstract}

Keywords---brochure, educational material, estimation, learning, observation.

\section{Introduction}

One of the challenges in higher education is to conceive the teaching-learning process so that the student assumes an active position in it, that this motivates him, stimulates him to think, to suppose and to value, to propose an intellectual work to his Reach and progressively demanding. Research carried out by the Central Institute of Pedagogical Sciences, directed among others by Labarrere (1996); Roco (1996); López \& Pozo (2014); Valdés (1998); Lewalter, (2003); Kirschner, (2001); show that in the teaching-learning process there is an emphasis on the cognitive instruction, focusing on the actions of the teacher and to a lesser extent that of the students, which affects the development of personal resources for the critical reflection of the contents which entails that it is learned in a reproductive way and does not evaluate with appropriate evaluative criteria and the existence of limitations in the development of skills to determine its deficiencies.

Some previous research was found, among which Mosquera (2009); stand out; Kindelán (2007) among others that deal with topics such as materials related to the Pioneer Scouting Movement, which allows students to prepare for life in the countryside and camping; booklets containing games to promote the love of nature, there is also multimedia related to the activity of exploration and methodological alternatives for teaching the orientation career. The most recent have been those of the author Rosabal \& Aragon (2010) with the title: Didactic supports such as software and brochure for the theoretical preparation of the content of the cabulería and that of Padilla Castañeda (2013) with didactic Materials of the career of orientation so that the existing supports are not sufficient to favor

ISSN 2632-9425

Submitted: March 18, 2020 / Revised: April 27, 2020 / Accepted: May 09, 2020 
theoretical-practical preparation to other topics included in Theme I Recreational teaching camps: Basic camping techniques, which lack the didactic treatment of other contents of the Recreation as is that of observation and estimation within the teaching and learning process, so it is possible to detect the following deficiencies: Insufficient study materials, which allow the appropriation of the content of observation and estimation to students. Poor preparation of students about the methodology, terms, and definitions in observation and estimation.

From the elements mentioned above and the need for a theoretical-practical preparation that allows the basis for the understanding and execution of the contents of the observation and estimation, the following scientific problem is formulated: How to raise the theoretical-practical preparation of the content of the observation and estimation in the subject Recreational activities in nature in fourth-year students of the Physical Culture of the Faculty Santiago de Cuba? The following objective was elaborated: To elaborate a didactic material (Brochure) that provides the development of the theoretical-practical preparation in the content of the observation and estimation for fourth-year students of the Physical Culture career of the Santiago de Cuba Faculty. Teaching materials are all those components of the teaching and learning process that serve as material support for teaching methods to enable the achievement of the objectives set. The practical classes to promote activities that promote theoretical and practical preparation in the students are fundamentally framed in inadequacies in the basic preparation in terms of the development of the Observation and Estimation methodology which can be consolidated from individual training.

Consequently, based on researchers recognized as Pavlov (1979); Vigostky (cited by Sánchez Ramírez (2009) makes an assessment about the teaching materials which allow the dialectical relationship between the image and the word which allow the development of thought In addition, what is proposed by Cubero (2010), cited by Sánchez Ramírez (2009), which refers to the relationship between images and communication that promote the expression of knowledge, ideas and concepts, is also assumed, as well as authors such as Labarre (1991); González Castro (1990); Álvarez Carlos (2000); cited by Sánchez Rodriguez (2009); make reference to the fact that the teaching materials promote motivation, understanding, explanation, systematization, interpretation, generalization of the content, in addition to promoting self-activity to promote self-development, so that teaching materials are developed as consequence of the social needs of man, and especially because of the scientific nature of learning and teaching. They should serve to improve the working and living conditions of teachers and students, at no time to dehumanize teaching. They must also contribute to the direct contact of man with the outside world, hence its importance and relevance in the subject of Recreation.

\section{Materials and Methods}

For this research the term didactic material is worked on: it is considered as a material medium (digitized or not), needed by teachers and students for the orientation of the teaching-learning process, which contains updated information and is used as a source of knowledge. The materials should not replace the educational and human function of the teacher since it is he who directs, organizes, and controls the teaching and learning process (Macías $e t$ al., 2018; Alava \& Martinez, 2019).

They motivate learning since they stimulate students from the psychic and practical point of view if they are used properly. Materials should be conceived as part of a system, in combination, so that each one performs a very specific activity. There are no more important materials than others, each of them has a role to play in the process. If some of the teaching materials fail at the time of class, it is necessary to restore the balance throughout the system.

For the research carried out, the 5 fourth-year groups of the Regular Day Course were used as a population with a total enrollment of 141 students, representing $100 \%$; selecting from them a sample of 2 groups with a total of 54 students, which represents $38.3 \%$, of the 5 are of the female sex that constitutes $9.3 \%$ and 49 of the male sex for $88.9 \%$; with average ages of 21 to 23 years. To carry out this research, a series of methods and techniques were selected that favored the information for the study of the subject, such as Proposals of the didactic material (brochure), for the theoretical-practical preparation of the subject of Recreational activities in nature (McMahon \& Forehand, 1978).

\section{Analysis and Discussion of Results}

For this research, the term "Tourist Recreation" pamphlet is used, which is included in the didactic materials considered as a means of teaching needed by teachers and students for the effective and rational orientation of the instruction and education process, which contains updated information and used as a source of knowledge by 
students. The course Recreational activities in nature, is part of the discipline of physical recreation and is located in the first semester of the 4th year of the regular day course, having special characteristics, and is that it concludes with a camp, in which the practical classes that are interrelated with the theoretical contents taught where the professional skills that are necessary to properly plan and execute the activities of recreation in particular and physical recreation, in general, will conclude.

The theme I should be directed to ensure that the student learns to live in camp conditions, participating in the organization of activities and the management system of the same. In this topic, the characteristics of the camp must be analyzed and the mastery of the life skills in the countryside, animation, night activities, a festival, and the bonfires is pursued. In the topic number II, it is directed to the management of the map, the compass and the orientation in the field should be a reason for particular attention for what it represents for the life in the campaign, the walk will provide an approach with nature, an aspect that the teacher must of trying to exploit to the fullest. The brochure that was prepared consists of all the updated information about the modalities that are developed within the Tourism Recreation Circles, with greater emphasis on observation and estimation as part of the content that is within the Subject I of the subject Recreational activities in nature and the others included in the brochure are competition modalities. It is understood by Observation to all activity carried out by the man that detects and assimilates the features of an element using the senses as main elements, in physical recreation, it is carried out through the Orientation March.

On the other hand, Estimation is approximate measures to determine the height, width, or distance that can be done by methods. The brochure was chosen as it is a way of synthesizing and at the same time providing updated information on the aspects related to the aforementioned subject. This work aims to show that, with the preparation of a printed brochure, classes can be developed positively, based on printed materials, which will be the link to achieve satisfactory results in the different activities programmed in the subject of Observation and estimation (Corless \& Tu, 1998; Ben-Akiva \& Morikawa, 1990). This will allow students to appreciate for themselves how these activities are carried out, and that they can reproduce it later, developing skills such as: (observe, execute, perform, summarize, among others).

The elaborated didactic material has as a general objective:

To provide the development of the theoretical-practical preparation in the content of the observation and estimation for fourth-year students, as well as the development of skills, promoting the organization of healthy activities in full contact with nature, which allows the improvement of the didactic process, contributing to the integral formation of the students of the degree in Physical Culture.

For which it is traced as specific objectives:

1) To guide the content of the observation and estimation in an easy way for the students.

2) Strengthen the skills, abilities, and skills in the observation and estimation from the link of the theoreticalpractical.

3) Direct the content to promote the leading role of the teacher and thus contribute to the preparation of the students.

4) Contribute to the modification of character and the creation of socially acceptable habits.

\section{Proposal for the teaching material}

In the postgraduate studies carried out, didactic materials have been developed for which the following requirements are determined, determined by Céspedes Paredes (2011) which point to:

Standards for the preparation of the didactic materials.

1) Credits of the institution that must appear in bold.

2) Teaching material for the necessary purpose or objective

3) Author (s)

4) Introduction (1 page). Existing trend and approach assumed by the authors. Material structure

5) Development. Historical-logical analysis of the topic

6) Address the issues in a logical order and to the course summary.

7) Methodological guidelines and the evaluation of the course

8) The bibliography that supports the material

9) Date of elaboration.

10)Content: Not less than 40 pages.

Taking into account these aspects an adaptation is made for those used in the undergraduate.

The printed booklet consists of the following structure:

1) Introduction: 
It is a teaching material for students in the 4th year of the career in Physical Culture and deals with the sports tourism program as a Recreation activity that takes place in tourist recreation circles directed and advised by the Physical Education professors and Recreation professors of the INDER.

2) Basic concepts:

On the different individual modalities to be developed in the RT Circles highlighting the Observation (Orientation March) and the Estimate of width and distance height.

3) Nomenclature:

Of the tracks and signals of the orientation march and estimation of height, width, and distance. Assessment of the proposal and how to access it.

During the development of this work, it was possible to appreciate the need that students in the 4th year of the Physical Culture career have of a theoretical-practical preparation for the improvement of their activities regarding the content Observation and Estimation, so that the didactic material proposed It allows you to develop skills, abilities, and values not only for your professional life but for a lifetime, responding to the problem and the fulfillment of the tasks proposed, starting by incorporating it into the faculty library and thus, giving access to all those interested in The matter.

\section{Conclusions}

The epistemological characterization allowed us to recognize the theoretical and practical inconsistencies that led to the need to treat the problem under investigation. The results of the diagnosis reveal the existence of the insufficiencies that the students possess in the content referred to Observation and Estimation, its relation with the diversity of didactic resources. The didactic material (printed booklet) was prepared for the theoretical-practical preparation of the content of the Observation and Estimation in fourth-year students of the Physical Culture career, which meets the proposed objective. The feasibility of the proposal was checked through an interview with specialists; considering it necessary for the theoretical-practical preparation in the content of the Observation and Estimation in the subject of Recreational Activities in Nature, which allows us to declare the fulfillment of the proposed objective.

\section{References}

Alava, E. E., \& Martinez, M. E. M. (2019). Impact of teaching-learning process for brain. International Journal of Health Sciences, 3(1), 33-40. https://doi.org/10.29332/ijhs.v3n1.304

Álvarez, C. G. (2000). Economía y política petrolera. Indepaz.

Ben-Akiva, M., \& Morikawa, T. (1990). Estimation of switching models from revealed preferences and stated intentions. Transportation Research Part A: General,24(6), 485-495. https://doi.org/10.1016/01912607(90)90037-7

Castañeda, AE (2013). Pedagogy, digital technologies and information and knowledge management in engineering education. Havana: Editorial Félix Varela.

Castro, VG (1990). Cuban dictionary of teaching aids and related terms. People and Education.

Corless, M., \& Tu, J. A. Y. (1998). State and input estimation for a class of uncertain systems. Automatica, 34(6), 757-764. https://doi.org/10.1016/S0005-1098(98)00013-2

Cubero, C. A. (2010).Picturing Transnationalism: Towards a cinematic logic of transnationalism Suomen Antropologi: Journal of the Finnish Anthropological Society Volume 35(4), 26-34.

Kindelan, K. (2007). Methodological alternatives for teaching the Orientation Degree. (Diploma work not published). Santiago de Cuba, Cuba: ISCF "Manuel Fajardo".

Kirschner, P. A. (2001). Using integrated electronic environments for collaborative teaching/learning. Learning and Instruction, 10, 1-9. https://doi.org/10.1016/S0959-4752(00)00021-9

LaBarre, L. (1991). OSI Internet Management: Management Information Base. Network Working Group RFC, 1214. Labarrere, A. (1996). Intelligence and creativity at school. Education Magazine , 88, 20-25.

Lewalter, D. (2003). Cognitive strategies for learning from static and dynamic visuals. Learning and Instruction, 13(2), 177-189. https://doi.org/10.1016/S0959-4752(02)00019-1

López-Íñiguez, G., \& Pozo, J. I. (2014). Like teacher, like student? Conceptions of children from traditional and constructive teachers regarding the teaching and learning of string instruments. Cognition and Instruction, 32(3), 
219-252. https://doi.org/10.1080/07370008.2014.918132

Macías, E. I. P., Cedeño, H. A. C., \& Chávez, G. M. R. (2018). Importance of Improving Resilience in TeachingLearning Process of Students with Disabilities. International Research Journal of Management, IT and Social Sciences, 5(2), 120-128.

McMahon, R. J., \& Forehand, R. (1978). Nonprescription behavior therapy: Effectiveness of a brochure in teaching mothers to correct their children's inappropriate mealtime behaviors. Behavior Therapy, 9(5), 814-820. https://doi.org/10.1016/S0005-7894(78)80012-4

Mosquera, A. (2009). Lotman's semiotics as a theory of knowledge. Enl @ ce: Venezuelan Magazine of Information, Technology and Knowledge, 6 (3), 63-78.

Padilla, D (2013). Orientation Career teaching materials for fourth year students. Diploma work in option to the Bachelor's Degree in Physical Culture not published. Santiago de Cuba. Cuba.

Paredes, M. C. (2011). Parent involvement as an instructional strategy: Academic parent-teacher teams (Doctoral dissertation, Arizona State University).

Pavlov, B. S. (1979). Basicity of an exponential system and Muckenhoupt's condition. In Doklady Akademii Nauk (Vol. 247, No. 1, pp. 37-40). Russian Academy of Sciences.

Roco, M. C. (1996). Multiphase flow: summary paper. Powder technology, 88(3), 275-284. https://doi.org/10.1016/S0032-5910(96)03131-2

Rosabal, D., \& Aragón, G. (2010). Epiphytic lichens in the coastal scrub of the Siboney-Juticí Ecological Reserve (Cuba). Botanica Complutensis, $34,21$.

Sánchez Ramírez, LC (2009). ICT in the dynamics of the training process for scientific research in Higher Education [doctoral thesis]. Santiago de Cuba: University of Oriente.

Sánchez Rodríguez, J. (2009). Virtual teaching platforms for educational environments.

Valdés, G. (1998). The world outside and inside schools: Language and immigrant children. Educational researcher, 27(6), 4-18. https://doi.org/10.3102\%2F0013189X027006004 